\title{
Posttransplant Root and Shoot Growth Periodicity of Sugar Maple
}

\author{
Lisa E. Richardson-Calfee, J. Roger Harris ${ }^{1}$, and Jody K. Fanelli \\ Department of Horticulture, Virginia Polytechnic Institute and State University, Blacksburg, \\ Virginia 24061
}

AdDITIONAL INDEX wORDs. balled-and-burlapped, container, pot-in-pot, seasonal, trunk, Acer saccharum

\begin{abstract}
Fundamental information regarding posttransplant root and shoot growth dynamics is needed to better understand transplant establishment. Seasonal patterns of root, shoot, and trunk growth of balled-and-burlapped and pot-in-pot (PIP) sugar maples (Acer saccharum Marsh.) transplanted at leaf drop (Nov. 2000), late fall (Dec. 2000), early spring (Mar. 2001), budbreak (Apr. 2001), or budset (July 2001) were measured and compared with nontransplanted field- and PIP-grown trees. All trees exhibited a pattern of maximum shoot extension, root growth, and trunk expansion in early May, late May, and early June, respectively. Maximum root growth was concurrent with early trunk expansion, both of which began when shoot growth was decreasing. Root growth was characterized by periods of abundant growth in late May and early June and less growth in summer and early fall. Transplanting at fall leaf drop, in late fall or spring, or at budbreak did not appear to radically disrupt the normal growth periodicity of sugar maple. However, transplanting at budset (summer) resulted in abundant root growth 11 weeks later than the period of maximum root growth in all other treatments. Our data indicate that similar amounts of root regeneration can be expected for irrigated July-transplanted trees as for trees transplanted in fall and spring. As well, our study provides evidence of root mortality during the winter and spring after the first posttransplant growing season. Although minimal root mortality was evident in nontransplanted field trees, substantial root mortality was evident in the nontransplanted PIP trees during winter and early spring.
\end{abstract}

Growth periodicity is generally conceived as a set pattern of growth incited by internal factors and influenced by environmental conditions (Morrow, 1950). The inherent alternation between periods of abundant root and shoot growth and little or no growth is thought to serve as a mechanism for coping with environmental stresses (Reich et al., 1980). Periodic root and shoot growth may occur simultaneously in an apparent coordinated fashion (e.g., Cripps, 1970; Harmer, 1990) or in an alternating pattern (Ploetz et al., 1993; Thaler and Pages, 1996). Many woody plants [e.g., apple (Malus domestica Borkh.), jarrah (Eucalyptus marginata Donn ex Sm.)] exhibit a bimodal pattern of root growth with periods of active root elongation occurring in late spring and autumn interspersed by a period of rest or reduced growth, often in summer (e.g., Cripps, 1970; Dell and Wallace, 1983). Although many authors reported the occurrence of root growth before spring budbreak or initial spring shoot elongation [Cedrus atlantica (Endl.) Manetti, Pinus nigra Arnold ssp. laricio Poir. var. corsicana Loud.] (e.g., Kaushal et al., 1989; Wargo, 1983), others observed root growth beginning after spring budbreak or concomitant with shoot growth [Picea sitchensis (Bong.) Carr., Corylus colurna L.] (Ford and Deans, 1977; Harris et al., 1995).

In many instances, one dominant factor may appear to dictate root and shoot growth periodicity, but in most situations, a combination of factors is responsible. Root growth periodicity depends on genetic species-specific responses (Wargo, 1983) to multiple interacting and interdependent factors such as unfavorable environmental conditions like drought or high temperatures (Lyr and Hoffman, 1967), top pruning (Gilman, 1990), both excesses and shortages of soil moisture content

Received for publication 20 Dec. 2005. Accepted for publication 26 Jan. 2007. We thank Dan Ward and Michelle Marini for their statistical advice and Allen Safrit for his tremendous help transplanting the trees.

${ }^{1}$ Corresponding author. E-mail: rharris@vt.edu.
(Bevington and Castle, 1985), transplanting (Harris et al., 2002; Wang and Zwiazek, 1999), stage of shoot development (Bevington and Castle, 1985; Cripps, 1970), and measurement method (Harris et al., 1995).

The functional balance hypothesis describes the growth relationship between roots and shoots as being continuously modified (Brouwer, 1983). As such, rhythmic root and shoot growth in trees results from feedback mechanisms associated with maintaining a favorable root:shoot ratio (Borchert, 1973) and may be a consequence of water stress incited by an unfavorable root:shoot ratio associated with rapid shoot growth (Harmer, 1990) or a decline in carbohydrate reserves during shoot elongation (e.g., Deans and Ford, 1986; Wargo, 1979).

Although many studies concluded fall planting to be superior to spring planting (Hinesley, 1986; Watson and Himelick, 1983; Witherspoon and Lumis, 1986), other studies concluded fall planting is inferior (Buckstrup and Bassuk, 2000; Larson, 1970; Watson et al., 1986) or has no advantage to spring planting (Harris et al., 2001; Watson and Himelick, 1982). For example, early fall-transplanted sugar maple and northern red oak (Quercus rubra L.) began root regeneration earlier and regenerated more roots in the first season after transplant than mid-fall- and spring-transplanted treatments (Harris et al., 2002), whereas fringe tree (Chionanthus virginicus L.) did not regenerate roots outside the transplanted root ball until early July regardless of season of transplant (Harris et al., 1996).

A more complete understanding of root system regeneration patterns and relationships between shoot and root growth of newly transplanted trees will enhance our fundamental knowledge of root ecology and transplant establishment, which can result in practices that hasten the establishment of transplanted landscape trees. The objectives of this study were to determine the periodicity (timing and magnitude) of first-season root, shoot, and trunk growth of sugar maples growing in field or container, 
the two most common production methods. Trees were either grown in the field and transplanted with root balls wrapped in burlap or container-grown in the pot-in-pot (PIP) system (Ruter, 1997) and transplanted at various times of the year.

\section{Materials and Methods}

Plant material. Lightly-branched, bareroot sugar maples (1.2 $\mathrm{m}$ tall) were obtained from J. Frank Schmidt and Sons Co. (Boring, Ore.) and grown in a nursery bed or PIP production system for 2 years at the Urban Horticulture Center, Blacksburg, Va. [U.S. Dept. Agr. plant hardiness zone 6a (U.S. Dept. of Agr., 1990), AHS plant heat zone 4 (American Horticultural Society, 1997)]. Field trees were planted $1.4 \mathrm{~m}$ apart in rows $4.3 \mathrm{~m}$ apart and fertilized with $1.5 \mathrm{~kg} \cdot 100 \mathrm{~m}^{2} \mathrm{~N}$ of a sulfurcoated, slow-release fertilizer $(27 \mathrm{~N}-1.3 \mathrm{P}-10 \mathrm{~K}$; Southern States Cooperative, Richmond, Va.). Soil type was a Groseclose silt loam (clayey, mixed, mesic Typic Hapludults) with pH 6.2. The PIP production system consisted of 51-L containers [45-cm top width $\times$ 40.6-cm height (B-15; Lerio, Mobile, Ala.)] fitted in 51-L socket containers spaced $1.2 \mathrm{~m}$ on center in rows $1.5 \mathrm{~m}$ apart. Container substrate consisted of unamended pine bark (pH 6.2). Trees were fertilized with $168 \mathrm{~g}$ of encapsulated slowrelease fertilizer [15N-3.9P-10K (Osmocote Plus, 8-9 Month Northern Formula; The Scotts Co., Marysville, Ohio)].

In Sept. 2000, 24 uniform-sized field-grown and PIP trees were selected for use in this project. Mean heights for fieldgrown and PIP trees (standard error of the mean in parentheses) were $2.62(0.07) \mathrm{m}$ and $2.84(0.08) \mathrm{m}$, respectively. Trunk diameters, $15 \mathrm{~cm}$ above the soil line, were 69.8 (3.0) $\mathrm{mm}$ and 72.0 (1.8) $\mathrm{mm}$ for field-grown and PIP trees, respectively.

Treatments. Treatments consisted of two production methods [balled-and-burlapped (B\&B) and PIP] and five transplant dates [3 Nov. 2000 (leaf drop), 8 Dec. 2000 (late fall), 16 Mar. 2001 (early spring), 13 Apr. 2001 (budbreak), and 13 July 2001 (budset)]. The July transplant date was the date when twig extension had stopped on at least four of five shoots being monitored on the nontransplanted control trees. A sixth treatment served as a nontransplanted control. Rhizotrons for the nontransplanted control plants were located in the PIP system and original nursery bed and could not be randomized in the same bed as the transplanted treatments. Subsequently, the experimental design consisted of a $2 \times 5$ factorial arranged in a completely randomized design and augmented with two nontransplanted controls (field and PIP trees). There were four single-tree replications of each treatment (B\&B/November, PIP/November, B\&B/December, PIP/December, B\&B/March, PIP/March, B\&B/April, PIP/April, B\&B/July, PIP/July, nontransplanted field, and nontransplanted PIP).

RHizotron CONSTRUCTION. Three types of rhizotrons (root observation chambers, described subsequently) were constructed. A field rhizotron (FR) was constructed for the nontransplanted field trees, PIP rhizotrons (PIPR) were constructed for the nontransplanted PIP trees, and aboveground rhizotrons (AGR) were constructed for all transplanted trees (Fig. 1A-C).

On 2 Sept. 2000, one FR with four root observation bays was constructed on the north side of four trees spaced $1.4 \mathrm{~m}$ apart in the nursery bed from which the transplanted trees were removed. The FR was constructed by excavating a trench $56 \mathrm{~cm}$ wide $\times 6 \mathrm{~m}$ long $\times 56 \mathrm{~cm}$ deep parallel to the nursery bed. Four bays, each $61 \mathrm{~cm}$ wide $\times 36 \mathrm{~cm}$ long and extending perpendicular from the trench to $30 \mathrm{~cm}$ from the base of the trees, were excavated by hand. Plywood retaining walls, held upright by fence stakes, were installed at the ends of each bay and the backside of the trench. Windows, $\approx 40 \mathrm{~cm}$ wide $\times 35 \mathrm{~cm}$ tall, were cut out of the plywood panels at the end of each bay. Each window was fitted with 6.4-mm-thick, clear polycarbonate plates (GE Worldwide Manufacturing Sites, Mount Vernon, Ind.) fastened to the interior of the plywood. Sealant (DAP Inc., Baltimore, Md.) was used to seal gaps between the plywood and clear plates. Light was excluded from the windows by plywood shutters and black plastic flaps attached above each shutter. The entire FR (trench plus four bays) was covered with plywood that was removed during measurements.

PIPRs were constructed by cutting $28 \times 28-\mathrm{cm}$ windows in the sides of 51-L containers and fitting the windows with clear polycarbonate plates. Sealant was applied around the interior perimeter of the windows. Trees transplanted into the PIPR were spaced $1.2 \mathrm{~m}$ on center in rows $1.5 \mathrm{~m}$ apart. The nontransplanted PIP trees were set into PIPRs on 2 Sept. 2000.

AGRs were constructed from Keeper-Uppers [KU (Lerio)], which are normally used to protect containerized trees from windthrow and extreme temperature fluctuations in the root zone (Kelting et al., 1998). KUs are black plastic, flat-topped, pyramidal, bottomless shells with square bases $(58 \times 58 \mathrm{~cm}$ wide and $38 \mathrm{~cm}$ tall) and circular openings (43 cm diameter) in the top. A $30 \times 30-\mathrm{cm}$ window was cut out on one side of each $\mathrm{KU}$ and fitted with clear polycarbonate plates. Windows were fastened to the interior of the KUs and sealant was applied around the interior perimeter of the window. Flaps of black plastic were taped above the windows to exclude light. Foilcovered, plastic bubble insulation (Reflectix Inc., Markleville, Ind.) was wrapped and glued around each rhizotron (except the area of the window) to stabilize soil and substrate temperatures. Removable foil insulation wraps were constructed to wrap around the windows and cover the black plastic flaps. Wraps were held in place with Velcro tabs (Velcro Brand Industrial Strength Fasteners; Velcro USA Inc., Manchester, N.H.). AGRs were spaced $1.2 \mathrm{~m}$ apart in beds that were $4.3 \mathrm{~m}$ apart and positioned so windows faced north.

Tree haRVest AND PLANTing. Field-grown trees were hand dug with $\approx 51$-cm-diameter root balls, wrapped with industrystandard copper sulfate-treated burlap (A.M. Leonard, Piqua, Ohio), and tightly laced with sisal twine (B\&B). Circling roots on PIP trees were pruned to prevent further circling and encourage root exploration into the surrounding soil and substrate. A dense layer $(\approx 1 \mathrm{~cm}$ thick) of roots on the bottoms of the root balls of all PIP trees was also removed.

Root balls were centered $\approx 2 \mathrm{~cm}$ from the AGR windows. After positioning the trees in the rhizotrons, a 1:1 v:v mixture of sphagnum peat and coarse sand was used to fill the space between the root balls and windows. All transplanted trees were floodirrigated after transplanting and mulched with $5 \mathrm{~cm}$ of shredded, mixed hardwood mulch. The nontransplanted PIP trees were fitted into PIPRs after pruning circling roots from the root ball exterior. Unamended pine bark ( $\mathrm{pH}$ 6.3) was used to fill the spaces between the root balls and PIPR windows. Except for installation of the FR, no modifications were made to the nontransplanted control trees in the field. The peat and sand mixture described previously was used to fill the space between both the root balls and AGR windows and the soil profile and FR windows.

Tree CARE: Fertilization, IRRIGATION, AND so ON. All trees were fertilized with $200 \mathrm{~g}$ of encapsulated slow-release fertilizer [15N-3.9P-10K (Osmocote Plus, 8-9 Month Northern 

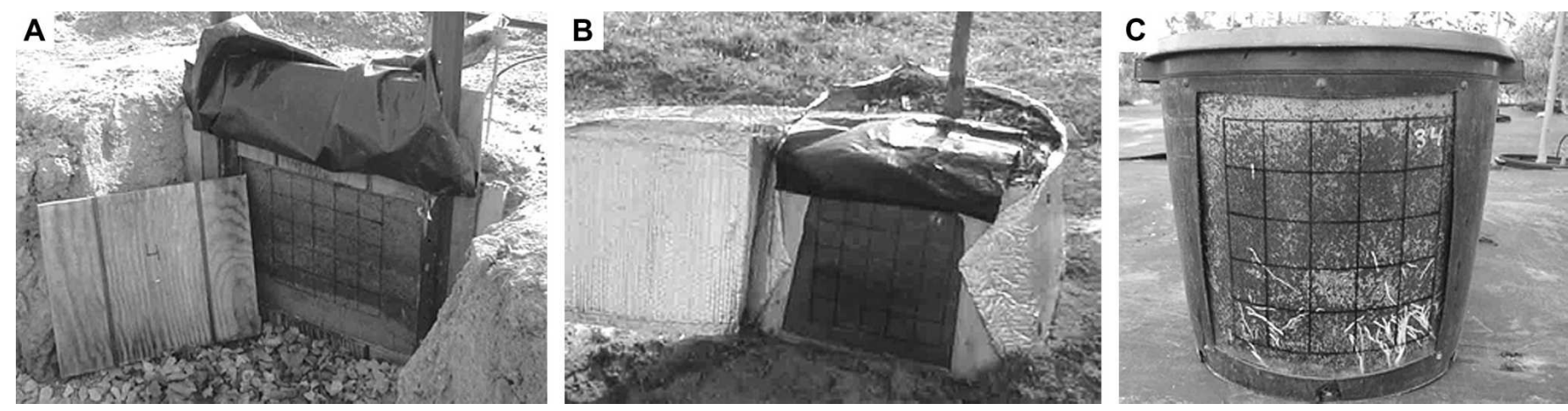

Fig. 1. Examples of (A) field rhizotron (FR), (B) aboveground rhizotron (AGR), and (C) pot-in-pot rhizotron (PIPR).

Formula)] just before spring budbreak each year. Trees were irrigated with a microirrigation system in such a manner as to maintain soil and substrate moisture near field or container capacity. During the first growing season (2001), trees in the AGR and FR were irrigated twice per week for $\approx 2 \mathrm{~h}$. Trees were irrigated approximately once a week during 2002 . Trees in the PIPR were irrigated twice per day for $15 \mathrm{~min}$ both years. Irrigation occurred less often when sufficient rainfall was received and during the winter months when trees were dormant. As a result of strong wind, two trees from the July transplant treatment had to be staked after transplanting. Survival was $100 \%$ for the B\&B trees. However, three PIP trees died over the course of the project. One tree from each of the March and April treatments died of unknown causes and another tree from the March treatment broke at the base of the trunk during a windstorm. All insect pest populations such as thrips and leafhoppers were closely monitored and controlled with appropriate insecticides.

Measurements. Root length, shoot extension, and trunk diameter of all trees were periodically measured from the time of installation of the control rhizotrons (2 Sept. 2000) until 10 June 2002. Growth of the nontransplanted B\&B and PIP trees was measured until 23 July 2002, at which time shoot extension had stopped and trunk expansion had slowed.

Periodic shoot growth for each tree was determined by obtaining the mean extension of five lateral shoots selected at budbreak in Spring 2001. Shoots were selected based on apparent potential for high vigor assessed by robustness (size and swelling) of the opening bud. When more than $50 \%$ of buds on an individual tree were open or had visible leaves, that tree was considered to have achieved budbreak. In instances when a selected shoot developed multiple terminal shoots and buds, the less dominant shoots were pinched back and measurements were taken on the remaining shoot.

Trunk diameter $15 \mathrm{~cm}$ above the soil or substrate line was measured on all trees just after transplanting or rhizotron installation. Trunks were marked to ensure the same measurement point at each consecutive measurement. Trunk diameter was the mean of two measurements, one made parallel and another made perpendicular to the nursery bed. Beginning at budbreak 2001, shoot extension and trunk expansion were measured weekly and every other week, respectively, except between fall leaf drop and spring budbreak when no measurements were made.

A $25 \times 25-\mathrm{cm}$ grid with lines in $5-\mathrm{cm}$ increments was drawn on the windows of all rhizotrons. Root length against the grids on the rhizotron windows was calculated using the line- intersect method (Marsh, 1971; Newman, 1966; Tennant, 1975), which uses a grid to approximate length. One count was assigned whenever a root crossed or touched a grid line. Two counts were assigned whenever a root segment lay along a line. Root-line intersections were counted by traversing the horizontal lines followed by the vertical lines. Counts were tallied and converted to length measurements using: $\mathrm{R}=[(11 /$ 14)(N)(grid unit)], where $\mathrm{N}=$ total root-line intersections and grid unit $=5 \mathrm{~cm}$. Roots that turned black or disappeared from the viewing area were considered dead (Jones et al., 2003; Pregitzer et al., 1995; Wang et al., 1995). Root length against rhizotron windows was estimated weekly until root growth appeared to have stopped for the winter. Root length was estimated monthly during winter. Weekly estimations resumed in early spring. As a result of the development of extraordinarily dense root mats in two of the nontransplanted PIP trees, where it became impossible to accurately count individual roots, the bottom row of the grid was eliminated on 18 Apr. 2001. A second row had to be eliminated on 9 Apr. 2002.

Soil and substrate temperatures were monitored with thermocouples (model HH21 Microprocessor Thermometer, Type J-K-T Thermocouple; Omega Engineering, Stamford, Conn.) placed $30 \mathrm{~cm}$ deep in a randomly selected AGR, PIPR, FR, and nursery bed. Afternoon temperatures were recorded twice per week for the duration of the project.

Analysis. Two types of graphs were generated to achieve a complete picture of posttransplant periodicity (scaled daily growth rate) and growth (accumulated biomass/standing crop). Standing crop refers to the amount of biomass that exists at a moment in time and may also be referred to as accumulated biomass. Although the periodicity graphs present data in such a manner that timing and relative magnitude of growth are emphasized, the accumulated biomass (standing crop) graphs provide a quantitative depiction of the cumulative changes in length and diameter among treatments.

Scaled daily growth rates were calculated for each individual tree by dividing the change in length (root and shoot) or diameter (trunk) for each measurement period by the maximum recorded measurement for the duration of the study and the number of days between measurements (Harris et al., 1995). The following equation was used: $\left\{\left[\left(\mathrm{T}_{\mathrm{x}}-\mathrm{T}_{\mathrm{x}-1}\right) / \mathrm{T}_{\max }\right] / \mathrm{N}\right\} \times$ 100 , where $T_{x}=$ measurement at time $x, T_{x-1}=$ measurement at time before $\mathrm{x}, \mathrm{T}_{\max }=$ maximum recorded measurement for the duration of the study (length or diameter), and $\mathrm{N}=$ number of days between $T_{x}$ and $T_{x-1}$. Daily growth rates were scaled to a percentage of the total growth to emphasize the timing and magnitude of shoot, trunk, and root growth and mortality for 
each individual treatment. Soil temperatures and treatment means of scaled daily growth rates were plotted over time to produce the seasonal patterns of growth and mortality (i.e., periodicity) of each treatment. Mean accumulated root length, shoot extension, and trunk expansion were plotted over time to highlight differences in magnitude of growth and the accumulated biomass (standing crop) graphs among treatments. Standard error was calculated for each treatment mean on each measurement day and plotted with the periodicity and growth curves.

\section{Results and Discussion}

Root systems are dynamic organs, in which growth (i.e., elongation of existing roots or initiation and elongation of new roots) and mortality occur simultaneously. In this study, root growth and mortality were not measured separately. Instead, root lengths reported in this study incorporate processes of both growth and mortality and reflect the cumulative changes in length density of live roots (standing crop). "Root growth" in the following text signifies instances in which growth exceeds mortality. Decreases in root length indicate mortality exceeding growth.

\section{Shoot growth}

Periodicity. Budbreak occurred in mid-April both years (Table 1 ). Maximum shoot extension rate occurred $\approx 2$ weeks after budbreak (Figs. 2 and 3). Shoot extension in 2001 ended 4 and 7 weeks after budbreak in the transplanted (17 May) and nontransplanted treatments (7 June), respectively. A much longer duration (1 May until 15 Aug.) of shoot growth was reported for a mature stand of sugar maples in the colder climate of central New York (USDA plant hardiness zone 5a) (Morrow, 1950). Although Morrow reported $85 \%$ of annual shoot extension being completed before 15 June, $85 \%$ of annual shoot extension (2001) in this study was completed by 10 May in the transplanted treatments (averaged across all transplant treatments except July) and 20 May in the nontransplanted treatments. The longer duration of shoot extension of the trees in Morrow's study was likely the result of seed provenance, tree age, and climate differences. Rapid early-season shoot extension has been reported in other temperate species. For example, $90 \%$ of annual shoot extension in american beech (Fagus grandifolia Ehrenb.) was completed within a 4-week period and the total period of growth lasted $\approx 60 \mathrm{~d}$ (Kienholz, 1941).

Accumulation of Biomass/standing Crop. Among B\&B treatments, the nontransplanted trees had more than twice the shoot extension during the first growing season (2001) as the transplanted trees (Fig. 4). Among PIP treatments, however,

Table 1. Median budbreak dates of balled-and-burlapped (B\&B) and pot-in-pot (PIP) sugar maple transplanted in Nov. and Dec. 2000 and Mar., Apr., and July $2001(\mathrm{n}=4)$.

\begin{tabular}{|c|c|c|c|c|}
\hline \multirow[b]{2}{*}{ Treatment } & \multicolumn{2}{|c|}{2001} & \multicolumn{2}{|c|}{2002} \\
\hline & B\&B & PIP & $\mathrm{B} \& \mathrm{~B}$ & PIP \\
\hline Nontransplanted & 17 Apr. & 19 Apr. & 19 Apr. & $20 \mathrm{Apr}$. \\
\hline November & 22 Apr. & 17 Apr. & 18 Apr. & 17 Apr. \\
\hline December & 16 Apr. & 24 Apr. & 19 Apr. & 21 Apr. \\
\hline March & 16 Apr. & 20 Apr. & 13 Apr. & 12 Apr. \\
\hline April & 23 Apr. & 23 Apr. & 20 Apr. & 19 Apr. \\
\hline July & - & - & 15 Apr. & 15 Apr. \\
\hline Overall median & 17 Apr. & 20 Apr. & 18/19Apr. & 18 Apr. \\
\hline
\end{tabular}

shoot extension of the nontransplanted and transplanted treatments was similar, except for the December and March treatments, which had less (Fig. 5). Reductions in shoot extension of the transplanted treatments may be partially attributed to the inadequacies of the newly transplanted root system at supplying sufficient moisture to drive maximum shoot extension (Alvim and Alvim, 1978). The terms "planting check" (Mullin, 1963) and "transplant shock" (Watson, 1986) have been used to refer to periods of prolonged reductions of top growth, which are presumably a consequence of an imbalance between the root system and crown that results from transplanting. These are temporary conditions of distress associated with injury, depleted reserves, and impaired functions relating to the adjustment to a new environment (Rietveld, 1989). The duration of planting check or transplant shock depends on the time necessary for the reestablishment of a root system capable of providing sufficient water and nutrients to the tree (Mullin, 1963).

\section{Trunk Growth}

Periodicity. Trunk expansion began as the rate of shoot extension began to decline with minimal overlap occurring between the periods of shoot extension and trunk expansion (Figs. 2 and 3). Although the seasonal beginning and end of trunk expansion were early June and early September in 2001, respectively, maximum trunk expansion occurred between 7 June and 5 July. Similarly, the beginning of trunk expansion occurred in 2002 when shoot extension had slowed and root growth was well underway. Morrow (1950) reported that trunk expansion of sugar maple paralleled and lasted 2 weeks longer than shoot extension and occurred between 1 May and 31 Aug. with $80 \%$ being complete by 1 July. In this study, however, $80 \%$ of total annual trunk expansion of transplanted and nontransplanted trees was achieved later (19 July and 2 Aug., respectively).

ACCUMulation OF Biomass/standing CROP. Trunk expansion of PIP trees was minimally affected by transplanting (Fig. 5). However, transplanting did result in reduced trunk expansion in the field-grown B\&B trees (Fig. 4). Differences between nontransplanted PIP and B\&B treatments are likely the result of inherent stresses associated with the smaller rooting volume of the PIPR. Similar to the reductions in shoot extension and trunk expansion exhibited by B\&B transplants in this study, Harris et al. (1998) reported that trunk expansion and twig extension of B\&B sugar maples were $29 \%$ and $18 \%$, respectively, of nontransplanted trees 2 years after transplanting. The July transplants were transplanted near the end of the period of trunk expansion and, as a consequence, most of their first-year growth was not recorded and appears minimal.

\section{Root Growth}

Periodicity. During the first season after transplant (2001), the onset of root length accumulation occurred between 9 May and 17 May. The period of maximum root growth occurred between 17 May and 14 June for all treatments except in the July transplants, which had not been transplanted at that time (Figs.2 and 3). Cessation of root growth, defined as the time when mortality outweighed growth, occurred between mid-July and mid-Sept. in 2001, depending on the treatment. In 2002, the onset of root growth occurred on 10 May, a time when considerable root mortality was still occurring in some individual trees. The maximum rate of root growth occurred in all treatments between the middle of and late May. 


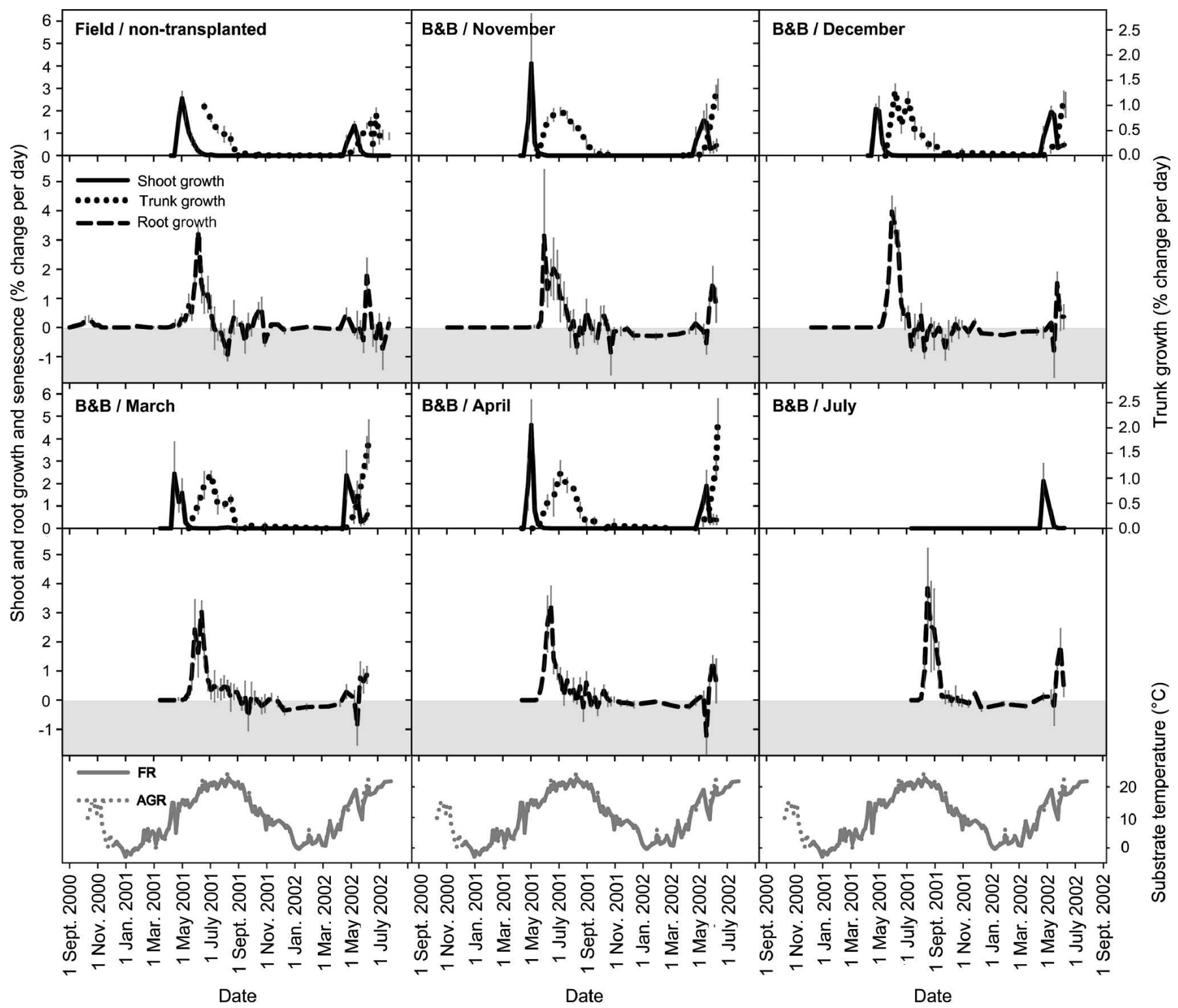

Fig. 2. Shoot, trunk, and root growth periodicity of balled-and-burlapped (B\&B) sugar maple transplanted in an aboveground rhizotron (AGR) in Nov. and Dec. 2000 and Mar., Apr., and July 2001. Nontransplanted trees remained in a field rhizotron (FR). Bars represent standard error; $n=4$. Trunk diameter growth of July transplants was completed before transplanting and is not presented.

Although Harris and Fanelli (1999) reported substantial root elongation in nontransplanted PIP sugar maples prior budbreak (1 Apr.), root growth or length accumulation in this study did not occur until much later (mid-May). Differences between the results of the Harris and Fanelli study and this study may be the result of year-to-year variation in weather. However, differences are more likely the result of measurement methods used in the studies. Harris and Fanelli followed individual roots to determine when roots were elongating. The line-intersect method was used in this study to quantify root length and individual roots were not followed. Therefore, data in this study reflect changes in standing root crop (i.e., total root length at a given moment in time). Root growth may have been occurring earlier but was not evident until growth processes outweighed mortality processes. In other words, overall root mortality could have been masking the growth of individual roots.
The period of maximum root length accumulation in this study was concurrent with trunk expansion, both of which began at the time when the rate of shoot extension was decreasing (Figs. 2 and 3). Similarly, Harris and Fanelli (1999) reported maximum root elongation corresponding to the end of the single flush of spring shoot extension $(\approx 1$ June $)$ in nontransplanted PIP sugar maple trees. Reduced root growth during periods of shoot expansion have been attributed to favored allocation of photosynthates to developing shoots (e.g., Bevington and Castle, 1985; Reich et al., 1980; Thaler and Pages, 1996). Dickson (1989) and Isebrands et al. (1994) found that little photosynthate produced in mature leaves was translocated to the root system during a flush of shoot growth. However, after leaves had fully expanded, more than $90 \%$ of photosynthate was translocated to roots (Dickson, 1991). Subsequently, as leaves expand and photosynthetic capacity 


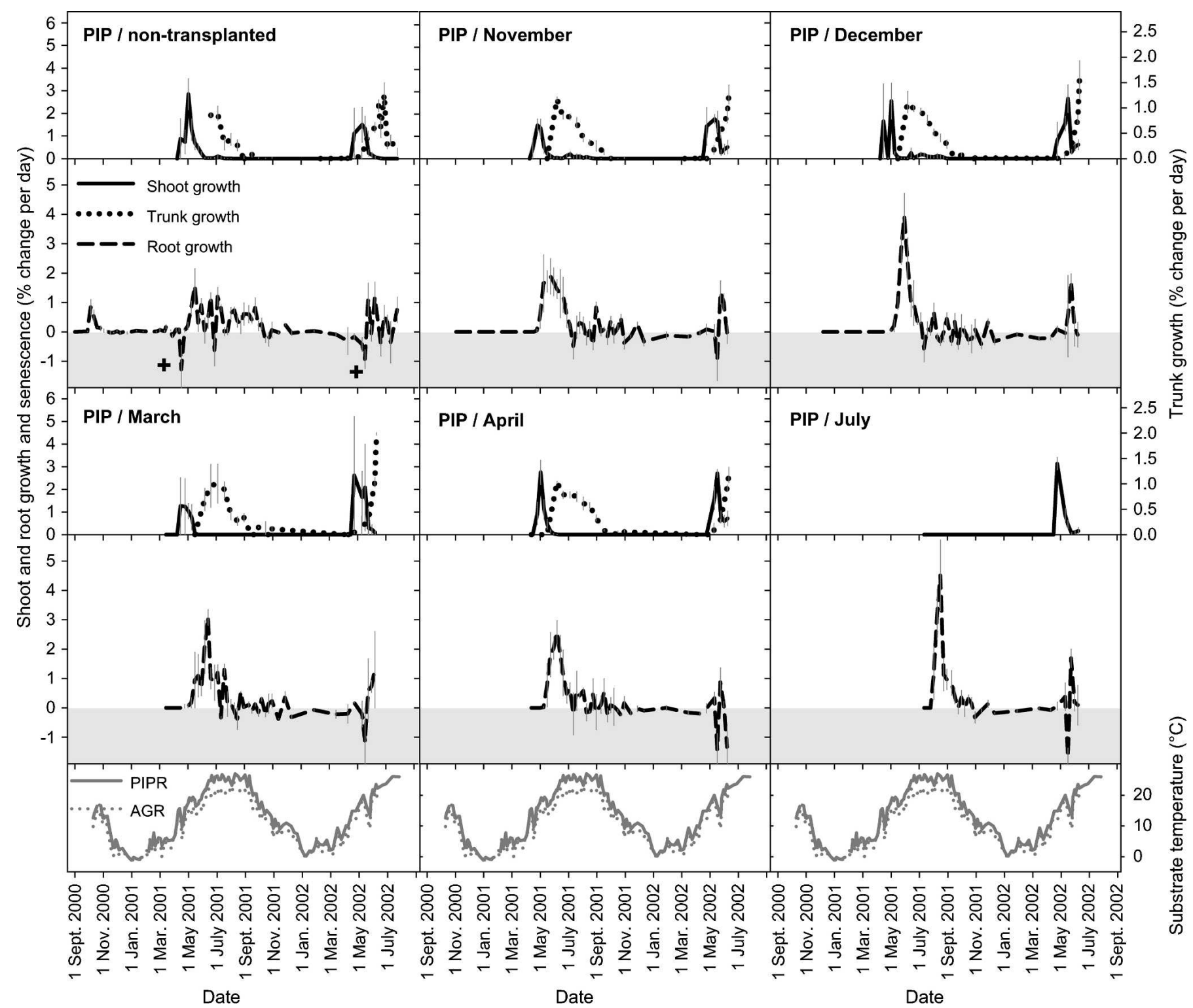

Fig. 3. Shoot, trunk, and root growth periodicity of pot-in-pot (PIP) sugar maple transplanted in an aboveground rhizotron (AGR) in Nov. and Dec. 2000 and Mar., Apr., and July 2001. Nontransplanted trees remained in a pot-in-pot rhizotron (PIPR). Bars represent standard error; $n=4 ;+=$ the elimination of the bottom row of a rhizotron grid resulting from the development of extraordinarily dense root mats in two nontransplanted PIP trees. Trunk diameter growth of July transplants was completed before transplanting and is not presented.

increases (Dickmann, 1971), shoots become a source of carbohydrates for the rest of the plant and root growth resumes.

Although Morrow (1950) reported that $80 \%$ of annual root growth on sugar maples in forests in New York occurred between mid-March and late June, $\approx 97 \%$ and $44 \%$ of annual (2001) accumulated root length of nontransplanted field and PIP trees, respectively, occurred by late June (Figs. 2 and 3). Although differences in root growth between trees in the PIPR and FR are likely a result of fewer roots being lost during installation of the FR and greater root turnover in the PIP production system (Richardson-Calfee, 2003), differences between trees in Morrow's study and the FR may be the result of tree age, which affects assimilate supply to roots and consequently the timing and duration of root growth (Deans and Ford, 1986).

Similar to Morrow (1950) who reported that root growth of mature sugar maple was greatest in spring and less in summer, root growth in this study followed a pattern of abundant growth in late May and June and less growth in summer and early fall. Morrow attributed the reduction and cessation of root growth during the summer and early fall to low soil moisture, primarily because he observed the resumption of root growth $2 \mathrm{~d}$ after rainfall. However, plants in this study were irrigated regularly and they still exhibited a reduced rate of root length accumulation during summer and early fall.

Regenerated roots were observed in the July transplants 3 weeks after transplant (2 Aug. 2001), a time when root growth had slowed in all other treatments. Root growth rate in the July transplants peaked on 16 Aug. (5 weeks posttransplant) and stopped around 15 Oct. (Figs. 2 and 3). Although the July transplants likely underwent a similar period of root growth in May and June, the unexpected, out-of-sequence spike in root growth for the July transplants could be thought of as a survival 


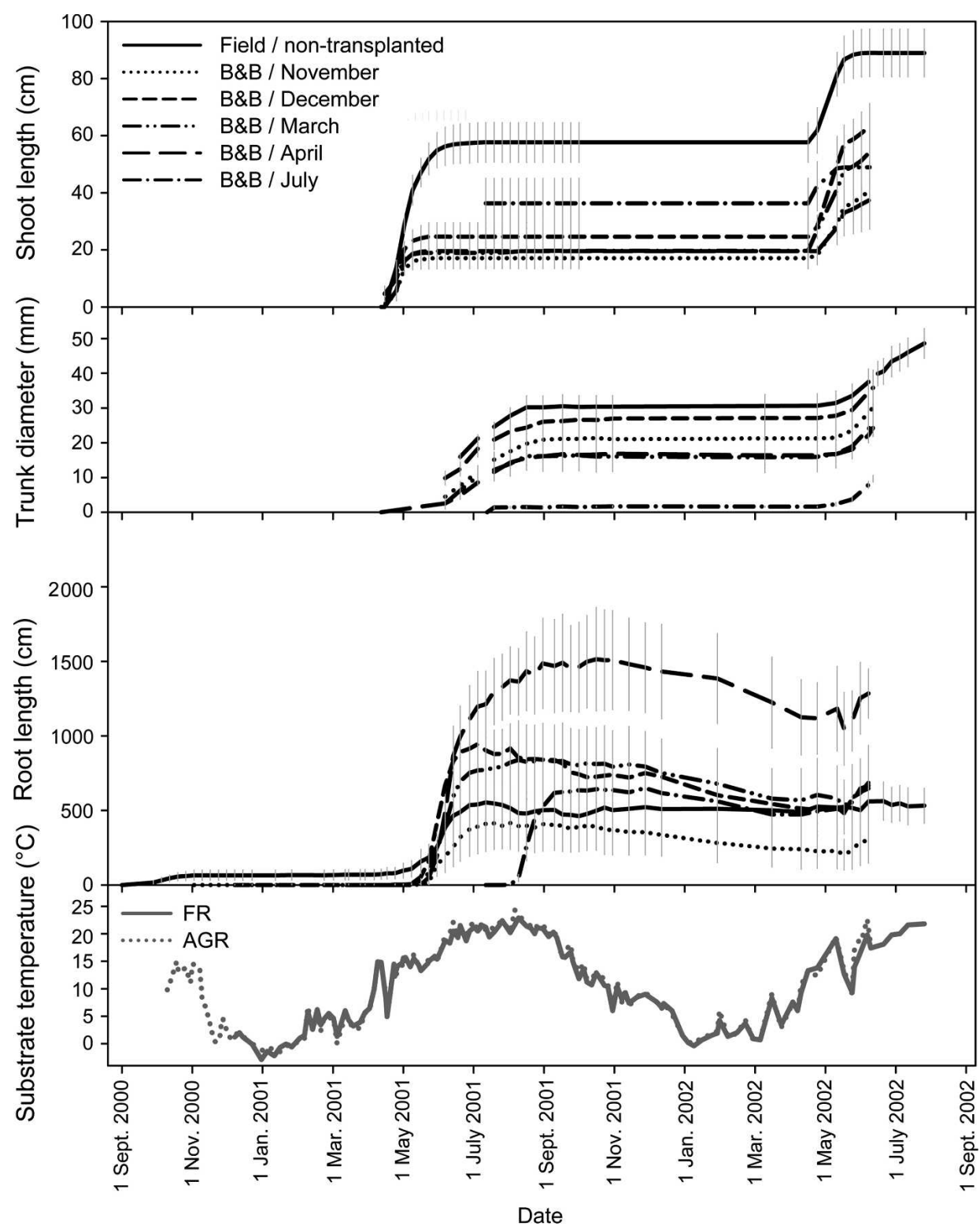

Fig. 4. Changes in standing shoot length, trunk diameter, and root length of balled-and-burlapped (B\&B) sugar maple transplanted in an aboveground rhizotron (AGR) in Nov. and Dec. 2000 and Mar., Apr., and July 2001. Nontransplanted trees remained in a field rhizotron (FR). Bars represent standard error; $\mathrm{n}=4$.

mechanism. Summer temperatures, a full canopy, and severed roots can quickly result in whole-plant desiccation and death unless close attention is paid to root ball moisture. Even with careful posttransplant management, many species would likely suffer. Although summer transplanting is generally not recommended, our data indicate that transplanting sugar maples in summer can be successful if proper soil moisture level is maintained after transplanting. Although spring offers warming soils, ample soil moisture, and a reduced potential for desiccation (Acquaah, 1999; Himelick, 1991), root regeneration potential may be highest during summer as a result of favorable conditions such as warm soil temperatures, long daylength, and fully developed tree crowns that are capable of producing carbohydrates that can be used for root growth (Watson et al., 1986). However, the risk of plant desiccation is usually highest during summer months. Thus, although irrigation is desirable for all transplanted trees, regular irrigation gains a higher level of importance for summer transplants.

Harris and Fanelli (1999) reported substantial root elongation after budset and until leaf drop (1 Nov.) when substrate temperatures dropped to 5 to $7{ }^{\circ} \mathrm{C}$. Root length accumulation occurred in the nontransplanted PIP trees in this study until late October, when temperatures were near $13{ }^{\circ} \mathrm{C}$ (Figs. 2 and 3 ). Afternoon substrate temperatures in the PIPR did not drop below $10{ }^{\circ} \mathrm{C}$ until after 12 Nov. in 2001. Therefore, root growth should not have been limited by temperature. Similarly, root length accumulation slowed in the nontransplanted field trees and transplanted trees between the middle of July and late October, before soil temperatures dropped to levels unfavorable for root growth. Lack of abundant root growth in fall, when soil temperatures and moisture were presumably nonlimiting, may be the result of internal growth mechanisms that dictate an inherent growth pattern that is mediated by environmental factors (e.g., soil moisture and temperature).

Both Harris and Fanelli (1999) and Morrow (1950) reported minimal root elongation in winter. Similarly, we observed minimal root length accumulation in the Winter of 2000-2001 in the nontransplanted trees (the transplanted trees had no apparent root growth at this time). In addition to low soil temperatures, lack of winter root growth is also a result of shoot dormancy (i.e., the absence of leaves) and the subsequent carbohydrate limitation (Cripps, 1970). Although minimal root growth occurred during the Winter of 2001-2002, root mortality dominated winter root activities of all treatments except the nontransplanted field trees (Figs. 2 and 3). Indeed, substantial mortality occurred in many treatments after 1 May 2002, around the time of budbreak and just before the spring flush of shoot growth. Stored carbon in roots is essential to growth of roots and leaves early in the growing season (Eissenstat and Yanai, 1997) and root carbon stores may become mobilized to supply carbon to newly growing shoots. Competition for assimilates between roots and shoots and the expense of maintenance respiration may be partly responsible for the observed winter and spring root mortality. Although Harris and Fanelli (1999) measured root elongation, we measured net root growth (root production minus mortality). Root mortality likely occurred in the other studies as well. 
Root length accumulation in the transplanted B\&B trees was greater than in the nontransplanted fieldgrown trees and was greater in the first growing season after transplant (Figs. 4 and 5). As well, reductions in shoot extension and trunk expansion were observed during the first growing season after transplant. Abod and Webster (1989) suggested that after a tree is transplanted, an optimal root length:leaf area ratio is reestablished by coordinating growth to correct the disrupted ratio such that pretransplant ratios are eventually reestablished (Kozlowski and Pallardy, 1997). Hence, major losses of roots resulting from transplanting should result in a corresponding period of reduced vigor in the crown (Watson et al., 1986) and increased root growth. The increased first-season rate of root length accumulation and decreased shoot and trunk growth of the transplanted treatments relative to the nontransplanted treatments likely reflect the coordination of growth to restore a more favorable root:shoot ratio. Maximizing root growth and reducing shoot growth favors the moisture balance of the transplant by potentially maximizing absorptive capability and minimizing transpirational losses. Watson et al. (1986) suggested that reductions in top growth were related to the time required for the replacement of the root system. Although it is possible that the reduction in root growth rate in 2002 was the result of root growth activity shifting to soil surrounding the AGR, most regenerated roots were found within the AGR and only minimal root exploration was evident outside of the footprint of the rhizotron on extraction of the root systems at the conclusion of the study. Trees in the PIPR did not exhibit such a drastic reduction of root growth during 2002 as observed in other treatments, which is likely the result of the sizeable root mortality that occurred during the winter and spring of 2001-2002 and the subsequent need to regenerate the lost portion of the root system to support the trees during summer months.

ACCUMUlation OF BiOMass/standing CROP. Among the B\&B treatments, April transplants had the greatest accumulation of root length by the end of the growing season and the greatest reduction of root length over winter (Fig. 4). Root growth in the $\mathrm{B} \& \mathrm{~B} /$ April transplants lasted $\approx 8$ weeks longer than the other $\mathrm{B} \& \mathrm{~B}$ treatments. Among PIP treatments, growth continued until much later in the season in the nontransplanted trees, resulting in the trees having nearly twice the accumulated root length as the transplanted trees (Fig. 5). The root systems of the nontransplanted PIP trees also underwent much greater mortality during winter and early spring. As a result of the development of a dense root mat in two trees in the PIPR, the bottom row of the rhizotron grid of each tree was eliminated. Had the root mat not been eliminated, root lengths of the nontransplanted PIP treatment would have been even higher, thereby accentuating any differences between the nontransplanted and transplanted PIP treatments.

The more extensive and later growth of nontransplanted PIP trees compared with transplanted PIP trees may have been the result of the root systems of the nontransplanted trees in the PIPR being bound by the containers. Subsequently, any root growth would more likely be detected, resulting in greater root length and possibly extending the timeframe of growth. 
Conversely, roots of the transplanted trees may have reached a density such that growth in the open-bottomed AGR was no longer favorable, and roots may have been growing in the ground below and around the AGR. Research of Jones et al. (2003) provides evidence of a resource-controlled carrying capacity for roots in the rhizosphere where root production in one individual is affected by root production of other individuals. Alternatively, differences in growth of the nontransplanted and transplanted PIP trees might be attributable to substrate temperatures and media factors (i.e., native soil versus pine bark). Summer temperatures in the PIPR were $\approx 3$ to $6{ }^{\circ} \mathrm{C}$ higher than any other location where temperature was measured but did not exceed $27^{\circ} \mathrm{C}$ at any measurement.

Also noteworthy was that in less than 8 weeks after transplanting, root length accumulations of the July treatments was similar to other transplanted trees and nontransplanted field trees (Figs. 4 and 5). Similar to all other treatments except the nontransplanted PIP and B\&B/April treatments, growth of the July-transplanted trees exhibited a leveling off of growth after $\approx 8$ weeks of growth. The finding that most trees had $\approx 8$ weeks of root growth, regardless of transplant date, suggests an inherent limitation that may be a result of limited resources in the rhizosphere or may be the result of limitations relating to the size root system that the tree can support.

Although standing root length of the nontransplanted field treatment remained relatively unchanged from 2001 to 2002, standing root length of the nontransplanted PIP treatment underwent substantial fluctuations (Figs. 4 and 5). Between late Jan. and mid-May 2002, standing root length in the PIPR decreased $31 \%$. Differences in reductions of standing root length may be the result of microenvironment differences between the types of rhizotrons. Late fall, winter, and early spring temperatures in the AGR and FR were nearly identical (within $1{ }^{\circ} \mathrm{C}$ ) (Fig. 4). However, cool-season temperatures in the PIPR were slightly $\left(1\right.$ to $3{ }^{\circ} \mathrm{C}$ ) higher than the AGR or FR (Fig. 5). Differences in substrate and soil characteristics may also have affected root mortality and decomposition. The substrate and soil of the AGRs and FR consisted of native soil (B\&B and nontransplanted field trees) or pine bark (PIP trees) with a layer of peat and sand between the root ball or soil profile and rhizotron windows, whereas all substrate in the PIPR consisted of unamended pine bark. The combination of pine bark media and higher temperatures may have contributed to increased soil microorganism activity (Head, 1973) and root decomposition.

Similar to the nontransplanted PIP treatment, all transplanted treatments underwent substantial reductions in standing root length during winter and early spring in 2001-2002. Watson and Himelick (1997) reported that although numerous roots are produced from each severed root end, in most cases, one root will become dominant with time and the remainder of the small roots will die (Watson, 1986). Eventually, the root system will begin to resemble the original root system in both structure and distribution. Thus, the first roots regenerated after a tree is transplanted may serve as "temporary" roots and not have as long of an inherent lifespan. Reductions in standing root length in our study may have been a result of the death of these "temporary" roots.

Increases in root length of all treatments during the first spring and summer after transplanting (2001) were markedly greater than increases in root length the next spring (2002; Figs. 4 and 5). Although root growth of the transplanted treatments was only measured until mid-June during 2002, significant root growth had occurred by this time in 2001 . The lack of abundant root growth in late May and early June may have been a result of root growth activity mostly occurring outside the bounds of the AGR. Root length density may also have reached a steady state in which it was no longer favorable for root exploration to occur in the AGR as a result of increased competition among roots for resources. Alternatively, root growth may have slowed as a result of a shifting root:shoot ratio. The increase in first-season rate of root length accumulation coupled with the reduction in shoot extension and trunk expansion of the transplanted treatments relative to nontransplanted treatments likely reflect the coordination of growth by the tree and compensatory growth of the root system to restore a more favorable root:shoot ratio (Abod and Webster, 1989) whereby absorptive capability is maximized and transpirational losses are minimized.

\section{Conclusions}

The objectives of this study were to determine the periodicity of first-season root, shoot, and trunk growth of B\&B and PIP sugar maples transplanted at various times of the year. A more complete understanding of root system regeneration patterns and relationships between shoot and root growth of newly transplanted trees will enhance our fundamental knowledge of root ecology and transplant establishment. Although shoot extension and trunk expansion exhibited very uniform and well-defined patterns of growth, much greater variation existed for root growth and mortality with regard to time and duration. Overall, growth periodicity of transplanted and nontransplanted sugar maple followed a pattern of maximum shoot extension, root length accumulation, and trunk expansion in early May, late May, and mid-June, respectively (Figs. 2 and 3). The slight overlap in periods of shoot, trunk, and root growth activities indicates that considerable competition for assimilates and resources may occur, particularly in May and June when shoot growth is at a maximum and root and trunk growth are beginning activity.

Based on the observations in this study, transplanting in November, December, March, and April does not appear to radically disrupt the normal growth periodicity of sugar maple. However, July transplanting did disrupt the normal periodicity of root growth, resulting in a large spike in root growth 11 weeks later than the all other treatments (Figs. 2 and 3). As a result of the summer spike in root growth, the July transplants accumulated root lengths similar to other treatments by early September (Figs. 4 and 5). Our data indicate that with sugar maple, there is little advantage to fall and spring transplanting compared with summer transplanting regarding posttransplant root regeneration when proper soil moisture is maintained and careful handling procedures are practiced.

Although minimal root mortality occurred during winter in the nontransplanted field trees, significant reductions in root length occurred in most of the transplanted treatments during the winter and spring (Figs. 2-5). Competition for assimilates and a subsequent reallocation of resources within the plant may be partly responsible for the observed mortality of roots just prior maximum root elongation in spring. This finding supports the hypothesis of Watson et al. (1986) regarding the shedding of temporary roots. Finally, results of this study indicate that root systems of nontransplanted field-grown trees 
exhibit different growth dynamics than trees in a PIP production system, particularly with regard to root mortality. The cyclic nature of the standing root length in the PIPR may be of interest or relevance to persons studying nutrient and carbon cycling or working with containerized plants.

\section{Literature Cited}

Abod, S.A. and A.D. Webster. 1989. Root and shoot growth of newlytransplanted apple trees as affected by rootstock cultivar, defoliation and time after transplanting. J. Hort. Sci. 64:655-666.

Acquaah, G. 1999. Horticulture: Principles and practices. Prentice Hall, Upper Saddle River, N.J.

Alvim, P.D.T. and R. Alvim. 1978. Relation of climate to growth periodicity in tropical trees, p. 445-464. In: P.B. Tomlinson and M.H. Zimmerman (eds.). Tropical trees as living systems. Cambridge Univ. Press, N.Y.

American Horticultural Society. 1997. Plant heat zone map. American Horticultural Society, Alexandria, Va.

Bevington, K.B. and W.S. Castle. 1985. Annual root growth pattern of young citrus trees in relation to shoot growth, soil temperature, and soil water content. J. Amer. Soc. Hort. Sci. 110:840-845.

Borchert, R. 1973. Simulation of rhythmic tree growth under constant conditions. Physiol. Plant. 29:173-180.

Brouwer, R. 1983. Functional equilibrium: Sense or nonsense? Neth. J. Agr. Sci. 31:335-348.

Buckstrup, M.J. and N.L. Bassuk. 2000. Transplanting success of balled-and-burlapped versus bare-root trees in the urban landscape. J. Arboriculture 26:298-308.

Cripps, J.E.L. 1970. A seasonal pattern of apple root growth in Western Australia. J. Hort. Sci. 45:153-161.

Deans, J.D. and E.D. Ford. 1986. Seasonal patterns of radial root growth and starch dynamics in plantation-grown Sitka spruce trees of different ages. Tree Physiol. 1:241-251.

Dell, B. and I.M. Wallace. 1983. Periodicity of fine root growth in jarrah (Eucalyptus marginata Donn ex Sm.). Aust. J. Bot. 31: 247-254.

Dickmann, D.I. 1971. Photosynthesis and respiration by developing leaves of cottonwood (Populus deltoides Bartr.). Bot. Gaz. 132:253-259.

Dickson, R.E. 1989. Carbon and nitrogen allocation in trees. Ann. Sci. For. 46(suppl):631-647.

Dickson, R.E. 1991. Episodic growth and carbon physiology in northern red oak, p. 117-124. In: S.B. Laursen and J.F. DeBoe (eds.). The oak resource in the upper Midwest: Implications for management. Univ. of Minn., St. Paul, Minn.

Eissenstat, D.M. and R.D. Yanai. 1997. The ecology of root lifespan. Adv. Ecol. Res. 27:1-60.

Ford, E.D. and J.D. Deans. 1977. Growth of a Sitka spruce plantation: Spatial distribution and seasonal fluctuations of lengths, weights and carbohydrate concentrations of fine roots. Plant Soil 47:463-485.

Gilman, E.F. 1990. Tree root growth and development. I. Form, spread, depth and periodicity. J. Environ. Hort. 8:215-220.

Harmer, R. 1990. Relation of shoot growth phases in seedlings oak to development of the tap root, lateral roots and fine root tips. New Phytol. 115:23-27.

Harris, J.R., N.L. Bassuk, R.W. Zobel, and T.H. Whitlow. 1995. Root and shoot growth periodicity of green ash, scarlet oak, turkish hazelnut, and tree lilac. J. Amer. Soc. Hort. Sci. 120: 211-216.

Harris, J.R. and J. Fanelli. 1999. Root and shoot growth periodicity of pot-in-pot red and sugar maple. J. Environ. Hort. 17:80-83.

Harris, J.R., J. Fanelli, and P. Thrift. 2002. Transplant timing affects early root system regeneration of sugar maple and northern red oak. HortScience 37:984-987.

Harris, J.R., P. Knight, and J. Fanelli. 1996. Fall transplanting improves establishment of balled and burlapped fringe tree (Chionanthus virginicus L.). HortScience 31:1143-1145.
Harris, J.R., P. Knight, and J. Fanelli. 1998. Effect of root severance on growth of field-grown sugar maple. HortScience 33: 21-23.

Harris, J.R., R. Smith, and J. Fanelli. 2001. Transplant timing affects first-season root growth of turkish hazelnut. HortScience 36: 805-807.

Head, G.C. 1973. Shedding of roots, p. 237-293. In: T. Kozlowski (ed.). Shedding of plant parts. Academic Press, N.Y.

Himelick, E.B. 1991. Tree and shrub transplanting manual. International Society Arboriculture, Urbana, Ill.

Hinesley, L.E. 1986. Effect of transplanting time on growth and development of fraser fir seedlings. HortScience 21:65-66.

Isebrands, J.G., P.T. Tomlinson, and R.E. Dickson. 1994. Carbon fixation and allocation in northern red oak. U.S. Dept. Agr., Forest Serv., North Central Forest Expt. Sta. St. Paul, Minn. Gen. Tech. Rpt. $\mathrm{NC}-173$.

Jones, R.H., R.J. Mitchell, G.N. Stevens, and S.D. Pecot. 2003. Controls of fine root dynamics across a gradient of gap sizes in a pine woodland. Oceologia 134:132-143.

Kaushal, P., J.M. Guehl, and G. Aussenac. 1989. Differential growth response to atmospheric carbon dioxide enrichment in seedlings of Cedrus atlantica and Pinus nigra ssp. laricio var. corsicana. Can. J. For. Res. 19:1351-1358.

Kelting, M., J.R. Harris, J. Fanelli, and B. Appleton. 1998. Humatebased biostimulants affect early post-transplant root growth and sapflow of balled and burlapped red maple. HortScience 33: 342-344.

Kienholz, R. 1941. Seasonal course of height growth in some hardwoods in Connecticut. Ecology 22:249-258.

Kozlowski, T.T. and S.G. Pallardy. 1997. Physiology of woody plants. Academic Press, San Diego.

Larson, M.M. 1970. Root regeneration and early growth of red oak seedlings: Influence on soil temperature. For. Sci. 16:442-446.

Lyr, H. and G. Hoffman. 1967. Growth rates and growth periodicity of tree roots. Intl. Rev. For. Res. 2:181-236.

Marsh, B.A.B. 1971. Measurement of length in random arrangements of lines. J. Appl. Ecol. 8:265-267.

Morrow, R.R. 1950. Periodicity and growth of sugar maple surface layer roots. J. For. 48:875-881.

Mullin, R.E. 1963. Planting check in spruce. For. Chron. 39:252-269.

Newman, E.I. 1966. A method of estimating the total length of root in a sample. J. Appl. Ecol. 3:139-145.

Ploetz, R.C., J.L. Ramos, and J.L. Parrado. 1993. Periodicity of shoot and root growth in grafted avocado. Trop. Agr. 70:248-251.

Pregitzer, K.S., D.R. Zak, P.S. Curtis, M.E. Kubishke, J.A. Teeri, and C.S. Vogel. 1995. Atmospheric $\mathrm{CO}_{2}$, soil nitrogen and turnover of fine roots. New Phytol. 129:579-585.

Reich, P.B., R.O. Teskey, P.S. Johnson, and T.M. Hinckley. 1980. Periodic root and shoot growth in oak. For. Sci. 26:590-598.

Richardson-Calfee, L.E. 2003. Post-transplant root production, mortality, and periodicity of landscape-sized shade trees. Virginia Polytechnic Inst. State Univ., Blacksburg, PhD Diss.

Rietveld, J. 1989. Transplanting stress in bareroot conifer seedlings: Its development and progression to establishment. Northern J. Appl. For. 6:99-107.

Ruter, J.M. 1997. The practicality of pot-in-pot. Amer. Nurseryman $1: 32-37$.

Tennant, D. 1975. A test of a modified line intersect method of estimating root length. J. Ecol. 63:995-1001.

Thaler, P. and L. Pages. 1996. Periodicity in the development of the root system of young rubber trees (Hevea brasiliensis Muell. Arg.): Relationship with shoot development. Plant Cell Environ. 19:56-64. U.S. Dept. of Agr. 1990. Plant hardiness zone map. U.S. Dept. of Agr., Washington, D.C.

Wang, Y. and J.J. Zwiazek. 1999. Effects of early spring photosynthesis on carbohydrate content, bud flushing and root and shoot growth of Picea glauca bareroot seedlings. Scand. J. For. Res. 14:295-302. 
Wang, Z., W.H. Burch, P. Mou, R.H. Jones, and R.J. Mitchell. 1995. Accuracy of visible and ultraviolet light for estimating live root proportions with minirhizotrons. Ecology 76:2330-2334.

Wargo, P.M. 1979. Starch storage and radial growth in woody roots of sugar maple. Can. J. For. Res. 9:49-56.

Wargo, P.M. 1983. Effects and consequences of stress on root physiology. J. Arboriculture 9:173-176.

Watson, G.W. 1986. Cultural practices can influence root development for better transplanting success. J. Environ. Hort. 4:32-34.

Watson, G.W. and E.B. Himelick. 1982. Seasonal variation in root regeneration of transplanted trees. J. Arboriculture 8:305-310.
Watson, G.W. and E.B. Himelick. 1983. Root regeneration of shade trees following transplanting. J. Environ. Hort. 1:52-54.

Watson, G.W. and E.B. Himelick. 1997. Principles and practice of planting trees and shrubs. International Society of Arboriculture, Savoy, Ill.

Watson, G.W., E.B. Himelick, and E.T. Smiley. 1986. Twig growth of eight species of shade trees following transplanting. J. Arboriculture 12:241-245.

Witherspoon, W.R. and G.P. Lumis. 1986. Root regeneration, starch content, and root promoting activity in Tilia cordata cultivars at three different digging-planting times. J. Environ. Hort. 4:76-79. 